\title{
Murals INTERNACIONAL
}

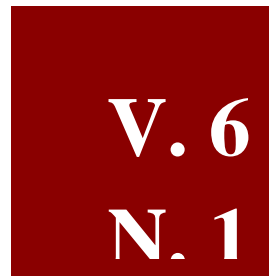

Rio de Janeiro

JAN-JUN 2015

ISSN 2177-7314

Mural Internacional é a revista eletrônica semestral do Programa de Pós-Graduação em Relações Internacionais da Universidade do Estado do Rio de Janeiro. Seu objetivo é debater temas relevantes das Relações Internacionais como a política internacional, políticas externas, economia política internacional, regionalismo, instituições internacionais, processos migratórios internacionais, relações culturais internacionais, discussões teóricas e/ou metodológicas e temas da atualidade de determinadas regiões.

As opiniões expressas nos artigos são de responsabilidade de seus respectivos autores.

Seu download é gratuito, a partir do site http://www.e-publicacoes.uerj.br/index.php/muralinternacional

\section{Editora:}

Miriam Gomes Saraiva

Assistente de Editoração:

Cristiane Ferreira Baptista

Revisão e Webdesign:

Cristiane Ferreira Baptista

Conselho Editorial:

Alexis Toríbio Dantas

Ana Paula Balthazar Tostes

Bruno de Moura Borges

Cláudio de Carvalho Silveira

Hugo Rogelio Suppo

Lená Medeiros de Menezes

Lia Cecília Baker Fonseca Valls Pereira

Marcelo Mello Valença

Maria Luisa Mendonça

Maurício Santoro Rocha

Mônica Leite Lessa

Paulo Afonso Velasco Junior

Williams da Silva Gonçalves

\section{Conselho Consultivo:}

Alejandro Simonoff (Universidad Nacional de La Plata)

Andrés Malamud (Universidade de Lisboa)

Anna Ayuso (CIDOB/Barcelona)

Antônio Carlos Lessa (Universidade de Brasília)

Clóvis Eugenio Georges Brigagão (Universidade Cândido Mendes)

Erica Simone Almeida Resende (IUPERJ/UCAM)

Fernando Roberto de Freitas Almeida (Universidade Federal Fluminense)

Franklin Trein (Universidade Federal do Rio de Janeiro)

Gelson Fonseca Júnior (Ministério de Relações Exteriores)

Gladys Teresita Lechini (Universidad Nacional de Rosario)

Javier Vadell (Pontifícia Universidade Católica de Minas Gerais)

José Briceño Ruiz (Universidad de Los Andes/Venezuela)

Letícia Pinheiro (IESP/Universidade do Estado do Rio de Janeiro)

Marcelo de Almeida Medeiros (Universidade Federal de Pernambuco)

Maria Regina Soares de Lima (IESP/Universidade do Estado do Rio de Janeiro)

Tullo Vigevani (Universidade Estadual Paulista Júlio de Mesquita Filho)

\section{Correspondência:}

Programa de Pós-Graduação em Relações Internacionais

Instituto de Filosofia e Ciências Sociais/Universidade do Estado do Rio de Janeiro

Rua São Francisco Xavier, 524, $9^{\circ}$ Andar, bloco F, sala 9037.

Rio de Janeiro - RJ CEP: .22071-030 Brasil

Realização:

Tel. (55) (21) 2334-0678 | E-mail: ppgri.revista@gmail.com 


\section{SUMÁRIO / TABLE OF CONTENTS}

DOSSIÊ: A Governança no Sistema Multilateral de Comércio e Finanças

DOSSIER: Governance in the multilateral system of commerce and finance

\section{CONTRIBUIÇÃO ESPECIAL / SPECIAL CONTRIBUTION:}

WTO - Challenges for the next 20 / OMC - Desafios para os próximos 20 anos VERA THORSTENSEN

4 - 11

Porque a OMC é importante para o Brasil? / Why is the WTO relevant to Brazil?

SANDRA POLÓNIA RIOS e PEDRO DA MOTTA VEIGA

12-21

Brasil frente al orden internacional liberal (2011-2013). Los límites de la posición reformista a la luz del régimen internacional de inversiones / Brazil in the liberal international order (20112013). The limits of the reformist position in the light of the international investment regime ESTEBAN ACTIS

22- 34

O G20 na governança global após a crise econômica de 2008/ The G20 in the global governance after the economic crisis of 2008

RAFAEL HENRIQUE DIAS MANZI

35-49

Perspectivas sobre a Regulação Financeira dos Estados Unidos em um contexto pós-crise / Perspectives about the US financial regulation in a post-crisis context

RODRIGO FAGUNDES CEZAR

50-64

\section{ARTIGOS / ARTICLES}

Memórias Institucionais e Política Global / Institutional Memories and Global Politics

MARCELO JAMES VASCONCELOS COUTINHO

65-83

When security matters: a hobbesian basis for the Responsibility to Protect principle / Quando a segurança é importante: bases hobbesianas para o princípio Responsabilidade de Proteger

MAÍRA SANTOS MATTHES

84-96

Identidades supranacionais / Supranational identities

LEANDRO GAVIÃO

97-115

As Bases Ideológicas do Realismo Periférico na Política Externa Argentina /

The ideological bases of the peripheral realism in Argentine foreign policy

MAURÍCIO SANTORO ROCHA

116-130

RESENHAS / BOOK REVIEWS

MACMILLAN, Margaret. A Primeira Guerra Mundial. São Paulo: Ed. Globo Livros, 2014, 724 p.

TOMAZ ESPÓSITO NETO

131-133

RUIZ, J. B.; SIMONOFF, A. (Org.) Integración y Cooperación Regional en América Latina: Una relectura a partir de la teoría de la autonomía. Buenos Aires: Biblos, 2015.

ANELISE DUTRA MACIEL DE ANDRADE

134-136 


\section{APRESENTAÇÃO}

\section{A governança no sistema multilateral de comércio e finanças}

A criação da Organização Mundial do Comércio (OMC) em 1995 foi celebrada como uma vitória do sistema multilateral, após o período de longa negociação da Rodada Uruguai (1986/1994) que ocorreu num cenário de proliferação de acordos preferenciais. Passados 20 anos de sua criação, a OMC vive um período de incertezas associado aos entraves para o avanço das negociações da Rodada Doha iniciada em 2001.

Convidamos três pesquisadores - Sandra Polónia Rios, Pedro da Motta Veiga e Vera Thorstensen Thorstein, com notório conhecimento sobre a OMC para escreverem sobre esse tema. Os artigos apresentam diagnósticos similares. A entrada da China na OMC, a crescente importância no comércio mundial dos países em desenvolvimento e, em especial, das "economias emergentes", a fragmentação da produção em cadeias globais/regionais de valor, a demanda por harmonização/convergências de regras, entre outras questões colocam novos desafios para o sistema multilateral. A preservação da Organização Mundial do Comércio é defendida pelos autores, porém é necessário repensar como organizar a governança numa instituição que agrega países com diferentes níveis de desenvolvimento e que adotam políticas domésticas muitas vezes conflitantes.

A demanda por harmonização/convergência/cooperação de regras domésticas para que se facilitem as novas formas de organização produtiva entra em choque com os diferentes sistemas de valor e culturais que regem grande parte dessas regulações. Normas técnicas, regras fitossanitárias, normas ambientais, regulações nos setores de serviços ganharam importância na agenda de negociações à medida que as barreiras transfronteiriças clássicas como as tarifas de importação tenderam a se reduzir. Como pensar a nova OMC e quais os desafios para o Brasil são os temas analisados pelos autores.

A crise de 2008 trouxe de volta um debate que se prolonga desde o término do sistema de câmbio fixo no início da década de 1970: a governança do sistema multilateral do sistema financeiro. Todos os artigos que foram enviados e aceitos pelo Conselho Editorial da Revista Mural Internacional que compõem esse dossiê abordam questões que mostram aspectos importantes no debate sobre a reforma do sistema financeiro.

O artigo de Rafael Henrique Dias Manzi analisa o papel do G-20 financeiro que foi criado em 1999, mas só ganhou destaque no debate sobre a reforma do sistema financeira com a crise de 2008. O autor mostra como o consenso criado no imediato pós-crise se desfez e as reformas consensuadas não foram implementadas até hoje como, o sistema de cotas do Fundo Monetário Internacional. A importância dos Estados Unidos, como um dos principais players no sistema financeiro global torna imperativo entender as mudanças na regulação financeira nesse país, pós-crise.

Rodrigo Fagundes Cezar irá analisar a Lei Dodd-Frank de 2010 a partir de uma perspectiva históricaestrutural mostrando as restrições da mesma para promover mudanças estruturais no sistema financeiro do país. Por último, o artigo de Esteban Actis estuda o comportamento do Brasil em relação aos Tratados Bilaterais de Investimentos e argumenta as limitações que o país apresenta para manter posturas reformistas em relação a alguns instrumentos da ordem liberal. Os tratados englobam aspectos relativos aos fluxos financeiros associados aos investimentos estrangeiros nos territórios domésticos.

Esperamos que os artigos aqui apresentados contribuam para o debate sobre a governança da ordem econômica multilateral, uma questão prioritária na agenda das relações econômicas internacionais. 